\title{
HACIA LA AUTOSOSTENIBILIDAD EN PROCESOS DE EXCAVACIÓN: CONSERVACIÓN PREVENTIVA Y GESTIÓN DE RIESGOS
}

\author{
Ana Pastor Pérez y y Olalla Canseco Domínguez²
}

\section{Resumen:}

La apuesta por la interdisciplinariedad en los equipos arqueopaleontológicos ha conducido a un aumento en la presencia de técnicos de conservación en excavaciones. El papel del restaurador de campo abarca desde la consolidación de estructuras in situ al transporte de piezas a depósitos, siendo menos frecuente su participación en las fases previas a la intervención arqueológica (planificación) o excavación. A través de nuevas metodologías de análisis, como la Gestión Integral de Riesgos (Instituto de Conservación Canadiense e ICCROM) y sus análogos en distintos países, podemos crear nuevas estrategias que permitan optimizar los recursos disponibles: anticiparnos al daño y elegir tratamientos más adecuados.

A lo largo de este estudio veremos cómo estas herramientas de gestión del patrimonio juegan un papel destacado por medio de la utilización de sistemas jerárquicos: a nivel de gestión de espacios y de los riesgos que afectan a los mismos. En estas disciplinas el conservador-restaurador pasa a tener un rol más dinámico en la toma de decisiones, colaborando en la selección de aquellas áreas que deben reservarse o excavarse (conservación espacial) de manera que se preserven el máximo de objetos, restos y estructuras (optimización de recursos). Los yacimientos arqueológicos en proceso de excavación suponen un reto que nos enfrenta a contextos en constante cambio. Esto dificulta llevar a cabo estrategias a medio y largo plazo debido a las modificaciones que se producen en torno a los hallazgos y áreas de estudio. En este paper veremos cómo la conservación preventiva en arqueología se ha impuesto a la curativa o a la restauración (definiciones según ICOM), destacando como técnica que potencia la auto-sostenibilidad ya que permite una anticipación a los riesgos, donde se propicie un mejor uso de los recursos económicos y humanos disponibles.

\section{Palabras clave:}

Conservación preventiva, Conservación espacial, Gestión del Patrimonio Arqueológico, Gestión de Riesgos, Autosostenibilidad

1 Licenciada en Historia. Diplomada en Conservación-Restauración de BBCC Arqueológicos. Master en Gestión del Patrimonio Cultural. Universidad de Barcelona. Doctorado Sociedad y Cultura. Grup d'Arqueologia Pública i Patrimoni.

a.pastor.restaura@gmail.com

2 Licenciada en Historia. Diplomada en Conservación-Restauración de BBCC Arqueológicos. Master Diagnístico del Estado del Patrimonio Histórico, Universidad Pablo Olavide (Sevilla). Ciemad. Centro Internacional de Estudios Multimedia de Arqueología en Madrid.

olalla.canseco@gmail.com 


\section{Abstract:}

The commitment to interdisciplinary teams in archaeopaleontological sites has led to an increase of technical conservation experts in excavations. A field conservator's role ranges from the consolidation of structures in situ to the deposit transport tasks, being less frequent its participation in the pre-intervention (planning) or archaeological excavation phases. Through new methodology's analysis such as Comprehensive Risk Management (Canadian Conservation Institute and ICCROM) or its analogues in different countries, we can create new strategies to optimize available resources: anticipate the damage and choose the most appropriate treatments to recover and prevent.

Throughout this study we will see how these management tools in the assessment and development of heritage play a prominent with the use of hierarchical systems both in terms of space and risks affecting the same role. Applying these new methodologies, the conservator-restorer will foster a higher dynamic role in decision-making process, collaborating in the selection of areas to be preserved or excavated (spatial conservation) permitting the maximum number of structures to be preserved (resource optimization). During archaeological excavation processes we face constantly context's changing, making it difficult to carry out med and long term strategies; changes occurring around the findings. Trough this paper we will examine how preventive conservation has been imposed on the curative/ remedial conservation or restoration (ICOM definitions) as a technique that enhances self-sustainability due to their qualities to better organize economic and human resources.

\section{Key words:}

Preventive conservation, Spatial Conservation, Archaeological Heritage Management, Risk Management, Self-sustainability

\section{Introducción}

El papel del conservador-restaurador de arqueología comienza a tener un protagonismo relevante en las últimas décadas ${ }^{3}$ debido a diversos factores que han conducido a una desartesanalización de la profesión. Por una parte, la proliferación de centros de interpretación y yacimientos musealizados —somos consumidores de monumentos, ya sea por motivos estéticos como identitarios/exis-

3 M. J.ALONSO LÓPEZ, M.J. "Conservación preventiva en excavaciones arqueológicas: el futuro del pasado", Pátina, 8: 1997, pp.116-123.

J. A. HERRÁEZ FERREIRO. "La conservación preventiva del arte rupestre", Actas de los VII Cursos Monográficos sobre el Patrimonio Histórico: [Reinosa, julio-agosto 1996], Universidad de Cantabria, Servicio de Publicaciones, Ayuntamiento de Reinosa: 1997, pp. 197-208. 
tenciales-,${ }^{4}$ y por otra la apertura de este tipo de estudios al ámbito universitario con el consiguiente aumento de publicaciones científicas al respecto. ${ }^{5}$ Los cambios que se han producido en la forma de abordar las excavaciones arqueológicas y el registro material también han contribuido a profesionalizar esta tarea.

Las leyes en torno al patrimonio arqueológico han ido priorizado actuaciones de tipo preventivo en contraposición a la excavación extensiva que ha perdurado durante décadas. ${ }^{6}$ Excavamos menos, pero con una serie de objetivos concretos en cada campaña que nos permiten optimizar una serie de recursos económicos y humanos que se han visto mermados en un contexto de crisis económica global. En este sentido, la conservación preventiva juega un rol destacado, pues aborda la conservación de estructuras y artefactos de forma indirecta, interfiriendo mínimamente en la composición intrínseca del bien cultural y asegurando su pervivencia para el disfrute de científicos y ciudadanía.

\section{Historia de la disciplina: paradigma actual}

Las variantes del concepto "patrimonio" han tenido un impacto inmediato en las estrategias para protegerlo y conservarlo. El año 1964 marcó un hito con las conclusiones de la Comisión Franceschini, al establecer la categoría del bene culturale, testimonio material de cultura por poseer valor de civilización. ${ }^{7}$ Este nuevo enfoque del patrimonio necesitaba nuevas estrategias que fuesen más allá de la intervención directa, siendo el ámbito anglosajón pionero en aportar soluciones innovadoras. En estos primeros momentos de andadura, la disciplina de la conservación preventiva se asoció fundamentalmente al museo. ${ }^{8}$

Habrá que esperar a la década de 1990 para que se produzca un avance abismal. El foco de atención pasó del estudio de los desencadenantes del deterioro al desarrollo de métodos globales ligados a un trabajo inserto en equipos multidisciplinares. Las figuras que lideraron el cambio fueron Stefan Michalski y Robert Waller, seguidos unos años después por Jonathan Ashley-Smith. ${ }^{9}$ Será también en

4 C. GOULDING: "Romancing the past: heritage visiting and the nostalgic consumer", Psychology and Marketing, 18, 6 (2001), pp. 565-592.

5 M.J. ALONSO LÓPEZ. "Los estudios superiores de conservación y restauración de bienes culturales", Las enseñanzas artísticas superiores en el Espacio Europeo de Educación Superior. Secretaría General de Educación, Servicio de Publicaciones, Madrid: 2010, pp.71-94.

4 M.A. QUEROL: Manual de gestión del patrimonio cultural. Akal, Madrid: 2010.

7 F. HERNÁNDEZ HERNÁNDEZ: "La conservación integral del patrimonio". Complutum Extra, 6, 2 (1996), pp. 251-260.

8 I. GARCÍA FERNÁNDEZ: La conservación preventiva de bienes culturales. Alianza Editorial, Madrid, 2013, pp. 25-29.

9 I. GARCÍA FERNÁNDEZ: "Historia de la conservación preventiva. Parte II". Ge-conservación, 6 (2014), pp. 5- 18. 
este momento cuando la conservación preventiva comience a salir del museo, postulándose el campo de la arqueología como uno de los ámbitos por excelencia para su aplicación. ${ }^{10}$

Los avances conceptuales de la década anterior cristalizarán en un documento fundamental para la conservación europea: la Resolución de Vantaa de septiembre de 2000, Hacia una Estrategia Europea sobre Conservación Preventiva. ${ }^{11}$ Algunas de sus premisas fueron la prevención, la sostenibilidad y eficacia en la custodia del bien cultural como medios para asegurar su pervivencia. Aquí se indica la importancia de considerar una responsabilidad compartida, ${ }^{12}$ así como integrar la "conservación" en todos los momentos de la vida del bien cultural. ${ }^{13}$

En el campo de la arqueología dicha integración comienza a tomar fuerza a raíz del $5^{\circ}$ Congreso Mundial de Arqueología ( $5^{\text {th }}$ World Archaeological Congress), celebrado en Washington en 2003, cuyo título ya era toda una declaración de intenciones: Of the Past, for the Future: Integrating Archaeology and Conservation [Del pasado, para el Futuro: integrando Arqueología y Conservación]. ${ }^{14} \mathrm{La}$ conservación debía dejar de ser un elemento auxiliar, que se ocupaba tan sólo del cuidado de los objetos, para migrar hacia una posición destacada dentro de la disciplina arqueológica. El nuevo enfoque integrado superaría el cortoplacismo, ${ }^{15}$ inadecuado al manejar un patrimonio: bien finito y limitado que debemos legar a nuestros descendientes. Puntualizaremos, sin embargo, que todos estos postulados defendidos en el congreso eran deseos futuros y no realidades: tan sólo tres de las 61 ponencias presentadas estaban escritas por conservadores. ${ }^{16}$

En los años siguientes destaca la labor del Centro Internacional de Estudios de Conservación y Restauración de los Bienes Culturales, ICCROM, que lleva a cabo

10 M. J. ALONSO y J. M. IGLESIAS: “Arqueología y conservación preventiva: una convergencia lógica". Actas de los XX Cursos Monográficos sobre el Patrimonio Histórico: [Reinosa, julio de 2009]. Universidad de Cantabria, Servicio de Publicaciones, Ayuntamiento de Reinosa: 2010, pp.123-134. 11 COMISIÓN EUROPEA: "Hacia una estrategia europea sobre conservación preventiva". Adoptada en la reunión de Vantaa 21-22 de septiembre de 2000. European Commission, Vantaa, 2000.

12 I. KAPELOUZOU: "The inherent sharing of conservation decisions". Studies in Conservation, 57, 3 (2012), pp.172-182.

13 M. J. ALONSO LÓPEZ . "Conservación preventiva en excavaciones arqueológicas: el futuro del pasado". Pátina, 8 (1997), pp.116-123.

14 N. AGNEW y J. BRIDGELAND: Of the past, for the future: integrating archaeology and conservation. Proceedings of the conservation theme at the 5th World Archaeological Congress. Getty Publications, Los Angeles: 2006.

15 N. AGNEW y J. BRIDGELAND: Of the past, for the future: integrating archaeology and conservation. Proceedings of the conservation theme at the 5th World Archaeological Congress. Getty Publications, Los Angeles: 2006, pp.53-72.

16 C. SEASE: "Book reviews: of the past, for the future: integrating archaeology and conservation presents the papers of the conservation theme at the World Archaeological Congress (WAC), Washington DC, in June 2003". Studies in Conservation, 51, 4 (2006), pp.317-319. 
un importante programa de difusión de estrategias integradas. Los programas Built Heritage o Disaster and Risk Managment y su aplicación a través de cursos en distintos continentes dan prueba del carácter internacional y filántropo de esta institución. De igual modo, sucederá en las reuniones del Comité para la Conservación del Consejo Internacional de Museos, ICOM-CC, que en los últimos años trabajan en la autosostenibilidad aplicada a conservación. ${ }^{17}$ Recientemente, el enfoque holístico del Slow Movement ${ }^{18}$ ha tenido su repercusión en el campo de la conservación, siendo enunciado en el Slow Conservation Manifesto [Manifiesto para la Conservación Lenta]. Este documento en gran parte es deudor del pensamiento de John Ruskin y William Morris, quienes ya pusieron el acento en lo local y sostenible.

Con todas estas permutaciones en el marco conceptual, la ciencia arqueológica ha recogido el guante al reconocer que trabaja con bienes comunes que nos pertenecen a todos, herencia que debemos custodiar para transmitir a generaciones futuras. ${ }^{19}$ Esta responsabilidad implica que debemos incorporar nuevas orientaciones dentro de nuestra disciplina. La excavación no marca el inicio de la colaboración sino que ésta debe estar presente desde fases previas. El diseño del proyecto y la definición de unas necesidades económicas y humanas son aspectos fundamentales en los que la conservación preventiva debe aplicarse para garantizar el máximo aprovechamiento de los recursos disponibles. Esta interacción continuará durante la extracción, posterior almacenaje de artefactos, monitorización de estructuras o difusión y protección, ${ }^{20}$ entre otros. Es fundamental, por tanto, que la conservación se integre con la arqueología para lograr el objetivo común: conseguir salvaguardar la mayor cantidad de información posible sobre el pasado.

\section{El conservador: formación plural}

La formación de profesional en el campo de la conservación-restauración ha evolucionado en paralelo al concepto de patrimonio. De un perfil muy inter-

17 I. GARCÍA FERNÁNDEZ: La conservación preventiva de bienes culturales. Alianza Editorial, Madrid, 2013, pp. 25-26.

18 Desde el nacimiento del movimiento del "Slow Food" esta filosofía se ha aplicado a muchos otros aspectos de la vida, los viajes, los libros, la educación...pero todas se resumen en el acento en lo local, primando la sostenibilidad de sus acciones. No se rechaza el uso de la tecnología pero sí un uso más racional, apoyándonos en ella podemos ser selectivos en nuestras acciones e invertir el tiempo y esfuerzo justo.

19 C. JIMÉNEZ, D. SALAZAR y P. CORRALES: “De los alcances de la arqueología: redefiniendo fronteras". Conserva, 4 (2000), pp.71-85.

20 No debemos perder de vista en ningún momento del proceso que estamos trabajando con bienes únicos y no renovables. Aunque parezca una paradójico debemos conseguir que la excavación no suponga una destrucción de información o cuanto menos minimizar esta pérdida de datos. Esto solo es posible gracias a una estrategia integrada. 
vencionista en los años 1960 y 1970 se pasó, en los años 1980, a una etapa de revisión de las actuaciones anteriores. Los años 1990 son un momento de innovación, que destacan por la introducción de diferentes estrategias de conservación preventiva en distintos ámbitos, también en los currículos. En el caso español está presente en los planes académicos como materia ya en 1991, ${ }^{21}$ que dieron una nueva orientación a la disciplina y ampliaron el campo de acción del técnico. El conservador debe salir del laboratorio para acercarse a la realidad de los objetos que custodia; ahora ejercerá la tutela allí donde estén ubicados los bienes, evitando traslados perjudiciales y descontextualizaciones (Fig.1).

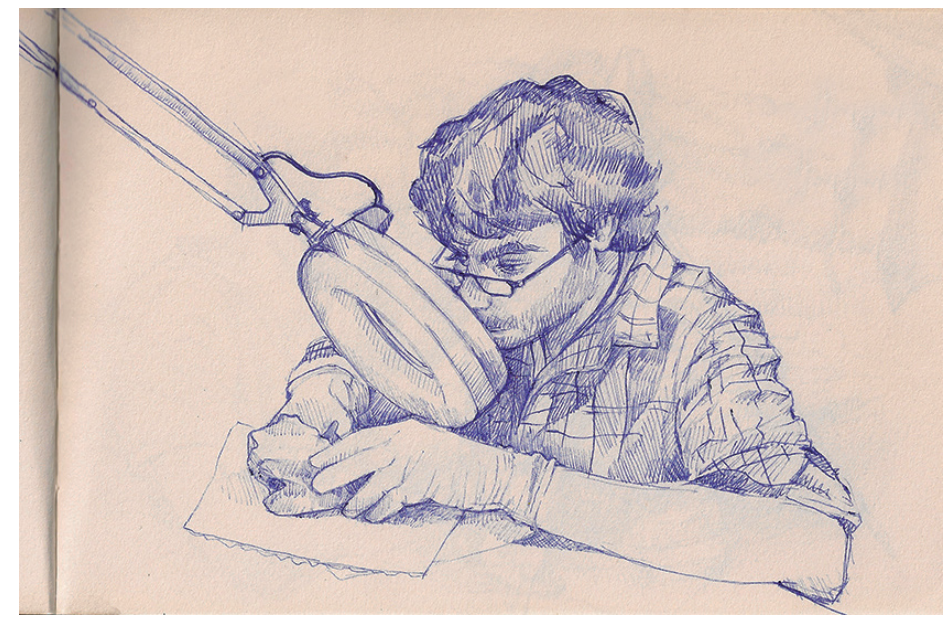

Fig. 1. Ilustración de Marga Lliso del Hoyo. "Abel restaurando bajo la lupa binocular". Dibujo realizado en el laboratorio de campo de los yacimientos de Pinilla del Valle. Madrid. España.

Con la introducción del Plan Bolonia en Europa se ha producido una unificación curricular en los grados de conservación restauración. Dos de las principales instituciones, European Network for Conservation-Restoration Education (ENCoRe) y la European Confederation of Conservator-Restorer's Organisations (ECCO), han diseñado el nuevo perfil profesional. El conservador-restaurador deberá estar capacitado para contextualizar el bien, entender su significado y abordar su carácter no renovable. El trabajo interdisciplinar será una prioridad y la preventiva tendrá el mismo nivel de importancia que la restauración. ${ }^{22}$

21 M. J. ALONSO y J. M. IGLESIAS: “Arqueología y conservación preventiva: una convergencia lógica". Actas de los XX Cursos Monográficos sobre el Patrimonio Histórico: [Reinosa, julio de 2009]. Universidad de Cantabria, Servicio de Publicaciones, Ayuntamiento de Reinosa: 2010, pp.123-134. 22 R. VIÑAS LUCAS: "La conservación y restauración de bienes culturales en el nuevo contexto educativo español". PH Boletín del Instituto Andaluz del Patrimonio Histórico, 66, Mayo 2008, pp. 106-123. 


\section{La unicidad del registro arqueológico y su problemática en conser- vación-restauración}

Mientras la interpretación del registro arqueológico se encuentra en pleno debate en los últimos tiempos, ${ }^{23}$ el conservador-restaurador de arqueología se enfrenta a la restauración de esos objetos que quedan en el olvido - no siempre en las condiciones de conservación idóneas - a la espera de una puesta en valor. Una de las premisas actuales de los documentos internacionales en cuanto a la salvaguarda del patrimonio, como remarca la Carta de Burra ${ }^{24}$ (ICOMOS-Australia) es la transmisión o pervivencia del mismo para el disfrute de futuras generaciones. La destrucción de los espacios/objetos arqueológicos se debe en la mayoría de casos a una falta de planificación inserta en el binomio conservación-excavación. Para ser capaces de crear buenas estrategias debemos analizar distintos escenarios y tener presente una cuestión de unicidad en cada caso de estudio (Fig. 2). Los distintos tipos de escenario podrían ser:

- yacimientos prospectados sin excavar,

- yacimientos en proceso de excavación,

- yacimientos excavados sin musealización,

- yacimientos musealizados,

- yacimientos integrados en edificios/plazas.

Cada uno de estos escenarios puede integrar peculiaridades: ubicarse en el medio urbano o medio rural, poseer o no con un centro de interpretación, estar gestionado por un ente autónomo, mayor o menor dificultad o facilidad de acceso, diverso impacto turístico... Independientemente de las características particulares de estos espacios, el papel del conservador-restaurador se basa en una serie de acciones - en algunos casos de tipo transversal — que se pueden desarrollar en distintos escenarios. Algunas de estas acciones son:

- poner en valor el sitio con distintos fines/objetivos,

- estipular unas estrategias/pautas de extracción-conservación-embalaje y transporte de los hallazgos/artefactos,

23 A. GONZÁLEZ RUIBAL: Reclaiming archaeology: beyond the tropes of modernity. Routledge, Milton Park Abingdon: 2013.

24 ICOMOS Australia: The Australia ICOMOS charter for the conservation of places of cultural significance (the Burra charter). Australia ICOMOS, Camberra, Australia: 2013. K. LARSEN (ed.): Nara conference on authenticity in relation to the World Heritage Convention: Nara, Japan, 1-6 November 1994. UNESCO World Heritage Centre, Paris:.1995. 
- analizar los riesgos del espacio a través de una metodología específica/adaptada,

- diseñar un plan de emergencias en caso de riesgo o catástrofe,

- monitorizar el estado de conservación del espacio.
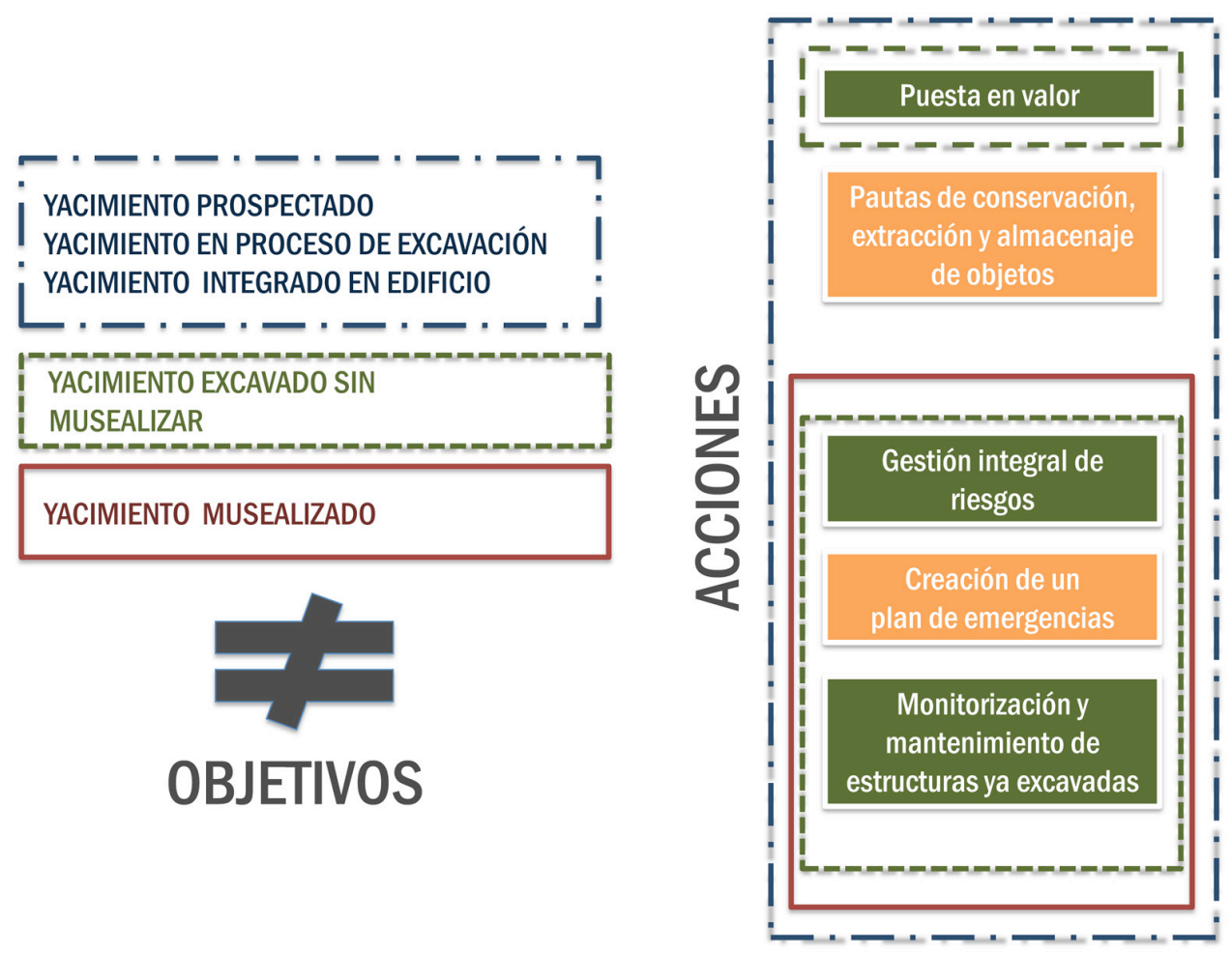

Fig. 2. Cuadro resumen donde se destacan los escenarios-acciones más habituales y el ámbito de actuación de los mismos.

Como podemos observar, el papel del restaurador puede ser determinante en todas las fases de vida de un espacio arqueológico. Desde el diseño/estudio de un sistema de cubiertas ${ }^{25}$ a la aportación de documentación en torno a procesos de restauración en un panel indicativo. Este profesional se pone a las órdenes de un equipo que suele estar compuesto por una serie de directores y técnicos especializados en distintos campos y que suelen tener objetivos diversos. Son

25 C. CABELLO-BRIONES: "A methodological approach to evaluate shelter effectiveness for the conservation of archaeological sites". en M. A. ROGERIO-CANDELERA, M. LAZZARI y E. CANO (eds.): Science and technology for the conservation of cultural heritage. CRC Press, Leiden: (2013), pp.41-44. 
muchas las ocasiones en las que la opinión de un conservador-restaurador puede ser opuesta a la de un arqueólogo, por ejemplo, extraer un artefacto o preservarlo hasta que las condiciones sean óptimas; decisiones que se asocian en parte a la acción destructiva que conlleva la excavación. Muchas de estas disputas se verían mitigadas si de antemano el conservador propone unas pautas y las comunica de forma abierta al equipo de excavación, desde sus directores hasta los voluntarios, haciendo partícipes de la tarea de preservar a todos los miembros del equipo. En el siguiente cuadro resumen hemos especificado el rol del conservador-restaurador en distintas fases (Tabla 1):

\begin{tabular}{|l|ll|}
\hline Planificación & - $\begin{array}{l}\text { Consulta de fuentes escritas y orales/ análisis de informes pasados/ legislación } \\
\text { vigente/ código deontológico/ sistematización de datos. }\end{array}$ \\
- & $\begin{array}{l}\text { Conocer el terrenos de antemano: estudio de condiciones climáticas/suelos/ } \\
\text { accesos/recursos. }\end{array}$ \\
- & $\begin{array}{l}\text { Elaboración de un presupuesto en función de las necesidades/objetivos que } \\
\text { haya marcado el equipo directivo. }\end{array}$ \\
- & $\begin{array}{l}\text { Preparar una base de datos coordinada con el resto de sistemas de registro de } \\
\text { información que se utilicen en la excavación. }\end{array}$ \\
- & $\begin{array}{l}\text { Requerir la colaboración de distintos especialistas en conservación-restaura- } \\
\text { ción: expertos en tratamientos de distintas estructuras (pintura mural, vidrio, } \\
\text { metal...). }\end{array}$ \\
- & $\begin{array}{l}\text { Determinar un margen de imprevistos técnicos y humanos. } \\
\text { Prospección }\end{array}$ \\
Reunir información relativa al entorno, así como al estado de conservación de \\
los elementos u objetos que vayamos encontrando en el caso de que sean visi- \\
bles/ sistematizar la información. \\
Embalar de forma correcta aquellos elementos que consideremos oportunos/ \\
elaborar una pauta de conservación preventiva para aquellas estructuras visi- \\
bles.
\end{tabular}




\begin{tabular}{|l|ll|}
\hline Excavación & Preparar un laboratorio de campo. \\
- & $\begin{array}{l}\text { Conocer las distintas necesidades de cada investigador asociado al equipo, de } \\
\text { forma que los tratamientos de extracción o consolidación no interfieran en sus } \\
\text { analíticas posteriores. }\end{array}$ \\
- & $\begin{array}{l}\text { Formar a distintos miembros del equipo para trabajar de forma conjunta en even- } \\
\text { tos complicados. }\end{array}$ \\
- & $\begin{array}{l}\text { Extraer artefactos de diversa naturaleza. } \\
\text { - }\end{array}$ \\
Consolidar estructuras de diversa índole. \\
-
\end{tabular}

Tabla 1. El papel del conservador-restaurador de arqueología.

Este cuadro busca hacer una síntesis de las tareas principales que debe llevar a cabo el profesional de la conservación de materiales arqueopaleontológicos. Es remarcable la labor de gestión que pondera en muchas de estas acciones y la problemática que ello conlleva en cuanto a la multiplicidad de agentes implicados o stakeholders. Como hemos indicado en la fase de excavación, sería oportuno llevar a cabo un registro de intervenciones y cotejarlo con las realizadas en otras campañas. En este punto es donde el conservador-restaurador suele tener más dificultades para desarrollar su labor al encontrarse con un problema de ac- 
ceso a la información generada. En muchos casos, al igual que sucede con otros técnicos, se trata de un especialista en prácticas no remunerado y desvinculado de forma permanente con el resto del equipo de investigación —alguien que se contacta únicamente cuando surgen imprevistos y dificultades que requieren de conocimientos especializados- ${ }^{26}$

A través del análisis de los beneficios que supone llevar a cabo un estudio previo de carácter preventivo, vamos a exponer de forma breve lo que creemos puede ser un avance en cuanto a conservación-restauración arqueológica se refiere: defender la postura del conservador-restaurador en la toma de decisiones previa a la excavación de un espacio arqueológico, y cómo ello puede derivar en beneficios a corto y largo plazo tanto de tipo social como económico.

\section{La gestión de riesgos aplicada en arqueología}

La gestión de riesgos en conservación de patrimonio integra distintos programas en los cuales se busca reunir herramientas que permitan identificar, analizar y evaluar las amenazas que se ciernen sobre los bienes culturales. Esta metodología comienza a aplicarse en museos como un sistema de prevención para el deterioro de las colecciones y poco a poco se ha ido adaptando a la arqueología. Algunos ejemplos más o menos conocidos son la guía Significance 2.0 utilizada en Australia, ${ }^{27}$ o en el caso de patrimonio urbano y paisaje el método DIVE de los Países Bálticos. ${ }^{28}$ Consideramos de interés la línea del reciente estudio en la ciudad de Cuenca (Ecuador), donde se ha realizado una aproximación al uso de los sistemas de información geográfica en conservación mediante el uso de una base geo-referencial ya existente llamada SISREDA (Sistema de Registro de Daños), la cual se aplica al patrimonio urbano, extrapolando datos de campos diversos (gestión, conservación preventiva y planificación urbana ${ }^{29}$ a un registro holístico. En el ámbito español destaca la Guía para un plan de colecciones ante emergencias ${ }^{30}$

26 R. NARDI y K. SCHNEIDER: "Site conservation during the rescue excavations" en W. AYLWARD (ed.): Excavations at Zeugma. The Packhard Humanities Institute, Los Altos, California: (2013), pp. $55-70$.

27 R. RUSSELL y K. WINKWORTH: Significance 2.0: a guide to assessing the significance of collections. Collections Council of Australia, Camberra: 2009.

28 D.A. REINAR y A. M.WESTERLIND: Urban heritage analysis. A handbook about DIVE. Riksantikvaren, Oslo: 2010

29 R. V. C. HERAS y A. WIJFFELS: "A value-based monitoring system to support heritage conservation planning". Journal of Cultural Heritage Management and Sustainable Development, 3 (2013), pp.130-147.

30 B. CULUBRET WORMS: Guía para un plan de protección de colecciones ante emergencias. Secretaría General Técnica, Ministerio de Cultura, Madrid: 2009. 
que precede a la creación del Plan Nacional de Conservación Preventiva. ${ }^{31}$ Excelentes trabajos como el reciente informe sobre la Cueva de Altamira ${ }^{32}$ denotan la importancia de llevar a cabo estudios integrales que incluyan entorno, historia, conservación o valores sociales del patrimonio, entre otros.

Desde principios del siglo XXI, el ICCROM (Roma), el Instituto de Conservación Canadiense y la Agencia de Patrimonio Cultural de los Países Bajos llevan a cabo distintos estudios en Gestión de Riesgos en Colecciones ${ }^{33}$ a través de una serie de cursos (destinados a expertos) donde el conocimiento se intercambia y construye a través de casos de estudio basados habitualmente en colecciones museísticas. Este método se desarrolla a través de una serie de etapas consecutivas — contexto, identificación y análisis de riesgos y tratamiento-, así como dos fases continuas — monitorización y consulta—. (Fig.3)

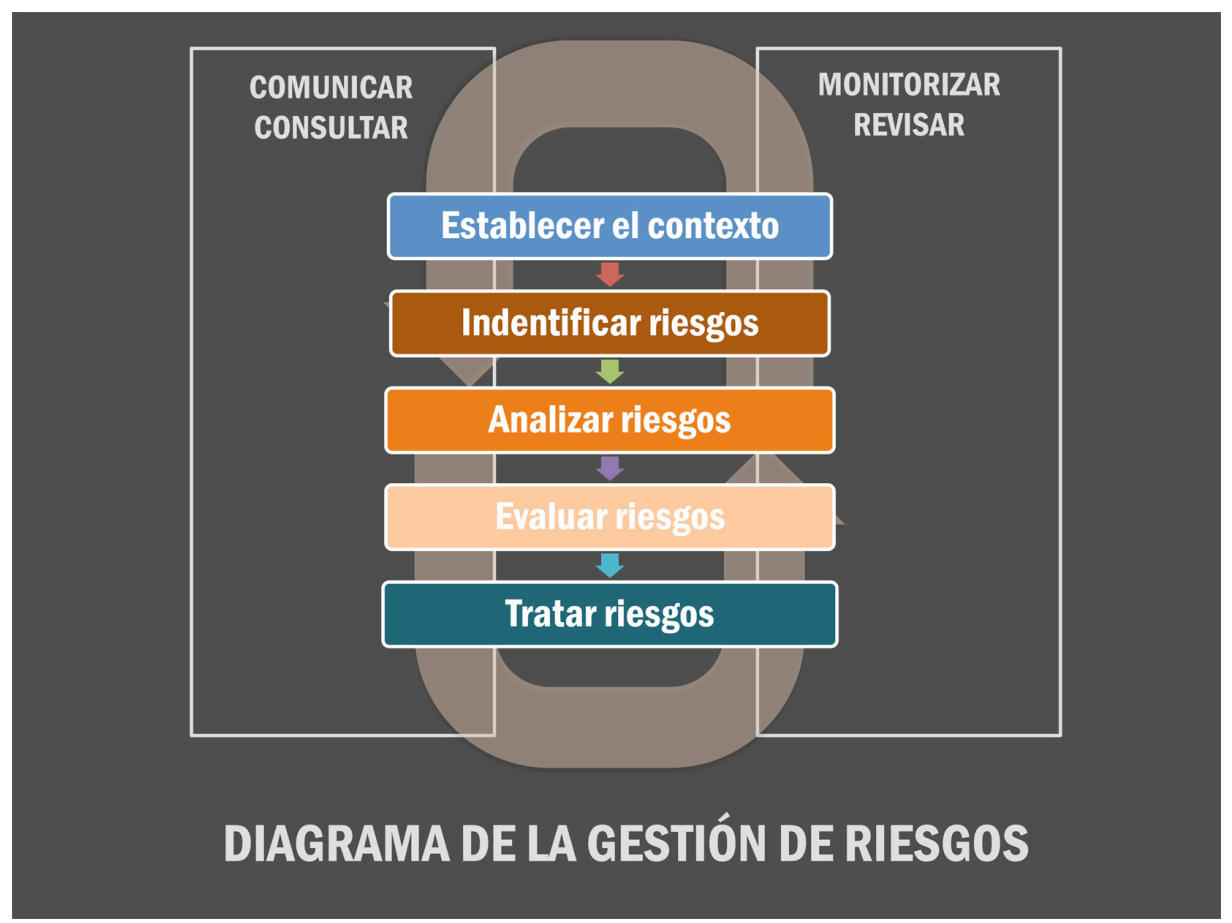

Fig.3. Ana Pastor. Inspirado en Michalski y Pedersoli (2009).

31 MINISTERIO DE EDUCACIÓN, CULTURA Y DEPORTE: Plan nacional de conservación preventiva. Ministerio de Educación, Cultura y Deporte, Madrid: 2011.

32 MINISTERIO DE EDUCACIÓN CULTURA Y DEPORTE: Programa de investigación para la conservación preventiva y régimen de acceso de la Cueva de Altamira (2012-2014). Ministerio de Educación, Cultura y Deporte, Madrid: 2014.

33 S. MICHALSKI y Z. PEDERSOLI: Manual de gestión de riesgo en colecciones. UNESCO, Paris: 2009. 
Dentro de la gestión de riesgos, el establecimiento del contexto o delimitación del alcance de trabajo resulta una tarea complicada en los yacimientos en proceso de excavación. Son distintos los motivos que nos pueden conducir a hacer un análisis de riesgos para el yacimiento arqueológico: proponer una nueva zona donde excavar (teniendo en cuenta el impacto en el paisaje o las dificultades de acceso), decidir qué tipo de especialistas son los más adecuados para trabajar en cada zona del yacimiento, proteger una determinada zona por encima de otra o elegir cuáles son los mejores tratamientos de restauración. Para ello tendremos que hacer una valoración previa, construir un diagrama de valor o herramienta similar que nos ayude a determinar qué espacios pueden ser más preciados para un fin concreto. El análisis de contexto/riesgos está ligado a una inversión de tiempo/recursos que podrá condicionar el tipo de estudio que realicemos, que abarque desde una gestión integral a un simple análisis de un riesgo en concreto, como podría ser una inundación estacional.

La valorización (necesaria para el establecimiento del contexto) es en sí controvertida si tenemos en cuenta la carga subjetiva que se produce en la valoración de un espacio. Los yacimientos arqueológicos en proceso de excavación varían en morfología y contenido a gran velocidad: un nuevo hallazgo único en un área determinada incrementará el valor de la misma. Este valor añadido/intrínseco ${ }^{34}$ podrá ser científico, histórico, estético, social, contextual, etc. ${ }^{35}$ Trabajar con una serie de valores que se denominan patrimoniales conlleva una serie de intenciones que no siempre quedan bien definidas y que en muchos casos anteponen los intereses administrativos/académicos a los sociales. ${ }^{36}$ Estos diagramas de valor serán determinantes a la hora de evaluar los riesgos a los que se halla expuesto un espacio patrimonial arqueológico, así como para la toma de decisiones en cuanto a los tratamientos aplicables. Hemos resumido las fases del método aplicado a arqueología en un cuadro-resumen (Tabla 2).

34 J. BALLART HERNÁNDEZ: El patrimonio histórico y arqueológico: valor y uso. Editorial Airel, Barcelona: 1997.

35 D. LOWENTHAL: "Stewarding the past in a perplexing present" en E. AVRAMI, R. MASON y M. DE LA TORRE (eds.): Values and heritage conservation. The Getty Conservation Institute, Los Angeles: 2000, pp.18-25. K. CLARK: "Values in cultural resource management" en G. SMITH, P. MESSENGER y H. SODERLANDS (eds.): Heritage values in contemporary society. Left Coast Press, Walnut Creek: 2009, pp. 89-99. D. COHEN, y M.O. FERNÁNDEZ REGUERA: Valoración de colecciones. Una herramienta para la gestión de riesgos en museos. Bogotá, Museo Nacional de Colombia: 2013. M. DE LA TORRE: "Values in heritage conservation: a project of the Getty Conservation Institute". APT Bulletin, 45, 2/3 (2014), pp.19-24.

36 M. MURZYN-KUPISZ y J. DZIALEK: "Cultural heritage in building and enhancing social capital". Journal of Cultural Heritage Management and Sustainable Development, 3, 1 (2013), pp.35-54.

A. PASTOR PÉREZ: Conservación preventiva y sinergias con la población local: el Barrio Gótico de Barcelona a través del Pla Barcino. Trabajo de Final de Máster. Universidad de Barcelona:2014 (Sin publicar). 


\begin{tabular}{|c|c|c|c|}
\hline Etapa & Elemento & Agentes & Supuesto/ Ejemplo \\
\hline \multirow[t]{5}{*}{ Contexto } & \multirow{5}{*}{$\begin{array}{l}\text { Diagrama de } \\
\text { valor }\end{array}$} & Valores del patrimonio & VALDRES ACADEMMCDS \\
\hline & & Fuentes escritas & \multirow{3}{*}{ 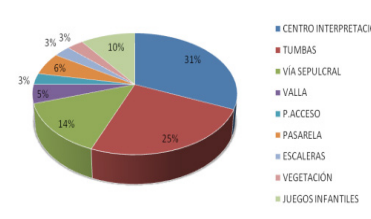 } \\
\hline & & Fuentes orales & \\
\hline & & Trabajo de campo & \\
\hline & & & $\begin{array}{l}\text { Diagrama de valor del ya- } \\
\text { cimiento musealizado de } \\
\text { la Vía Sepulcral Romana } \\
\text { (MUHBA, Barcelona, Es- } \\
\text { paña). Estudio de valores de } \\
\text { tipo académico: histórico, } \\
\text { estético, científico, simbólico, } \\
\text { educacional, social, unicidad } \\
\text { y económico. (Pastor 2014. } \\
\text { TFM. Universitat de Barcelo- } \\
\text { na. Sin publicar). }\end{array}$ \\
\hline Identificación de riesgos & Lista de riesgos & $\begin{array}{l}\text { Agentes de deterioro aso- } \\
\text { ciados a yacimientos } \\
\text { Fuego } \\
\text { Agua } \\
\text { Clima } \\
\text { Fuerzas físicas } \\
\text { Ondas electromagnéticas } \\
\text { Agentes biológicos } \\
\text { Contaminantes } \\
\text { Impacto indirecto de } \\
\text { actividades humanas } \\
\text { Riesgos conocidos al uso } \\
\text { de los materiales (fabric). }\end{array}$ & $\begin{array}{l}\text { - Merma de tareas de } \\
\text { mantenimiento forestal } \\
\text { en el entorno de ya- } \\
\text { cimiento } \\
\text { - Inundación de zonas } \\
\text { concretas del yacimiento } \\
\text { - Acumulación de hume- } \\
\text { dad por deshielo en } \\
\text { zonas del yacimiento } \\
\text { - Elevada eolicidad en una } \\
\text { determinada zona del } \\
\text { yacimiento } \\
\text { - Exceso de radiación } \\
\text { IR-UV en zonas con } \\
\text { policromía } \\
\text { - Presencia de madriguer- } \\
\text { as en distintas zonas del } \\
\text { yacimiento } \\
\text { - Proximidad de las } \\
\text { estructuras a zonas de } \\
\text { tráfico rodado } \\
\text { - Ignición intencionada de } \\
\text { elementos de protección } \\
\text { o señalización del ya- } \\
\text { cimiento } \\
\text { Erosión de pavimento } \\
\text { por ausencia de elemen- } \\
\text { tos de protección duran- } \\
\text { te su visita }\end{array}$ \\
\hline
\end{tabular}




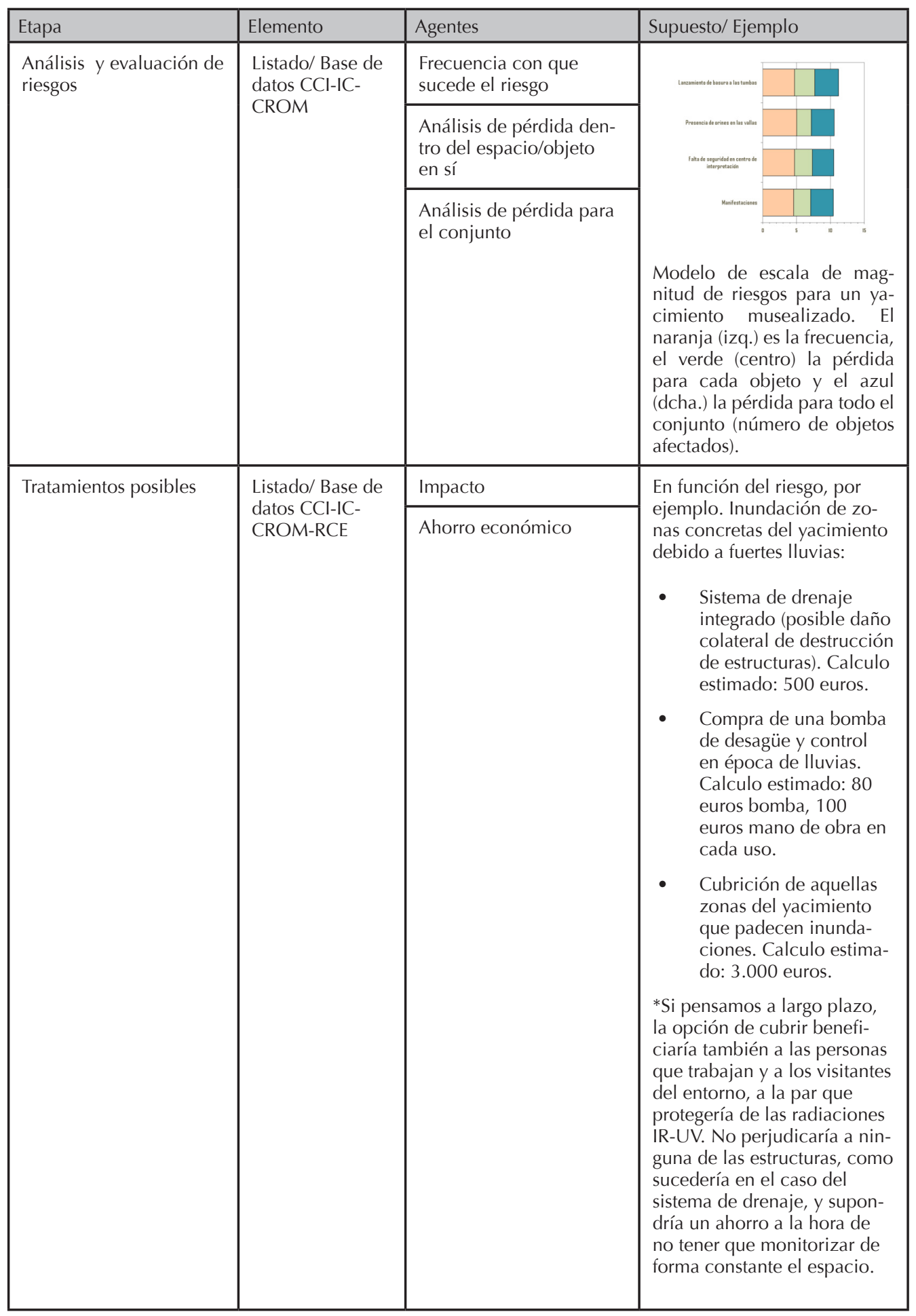




\begin{tabular}{|l|l|l|l|}
\hline Etapa & Elemento & Agentes & Supuesto/ Ejemplo \\
\hline Monitorización & 5 agentes de & Evitar & $\begin{array}{l}\text { En este apartado entran en } \\
\text { juego las políticas llevadas a } \\
\text { cabo por las autoridades re- } \\
\text { sponsables de los BBCC, así } \\
\text { como la inclusión de la ciu- } \\
\text { dadanía a través de una edu- } \\
\text { cación patrimonial. Sin duda } \\
\text { los habitantes o personas que } \\
\text { trabajan en el entorno serán } \\
\text { las primeras implicadas en } \\
\text { detectar qué riesgos se están } \\
\text { produciendo y hacer todo lo } \\
\text { posible por que se palie en } \\
\text { el menor tiempo posible. A } \\
\text { medida que aumenten los } \\
\text { programas de participación } \\
\text { yaumente el sentimiento de } \\
\text { pertenencia en la sociedad, el } \\
\text { patrimonio arqueológico ten- } \\
\text { drá más garantías de preser- } \\
\text { varse para el futuro, p. ej., Ad- } \\
\text { ministración pública, museos, } \\
\text { consorcios o demás entidades } \\
\text { para la salvaguarda y difusión } \\
\text { del patrimonio arqueológico. }\end{array}$ \\
& Responder \\
& Recuperar & \\
& & \\
& & \\
& & \\
& & \\
& & \\
& & \\
& &
\end{tabular}

Tabla 2. Resumen de las principales fases de la metodología de gestión de riesgos y su aplicación en el campo de la arqueología. Inspirado en los Cursos Reducing Risks in Cultural Heritage. ${ }^{37}$

Tras la participación de una de nosotras en uno de estos cursos (en el año 2011), pensamos que la aplicación de esta metodología podía aportar beneficios en el campo de la conservación-restauración arqueológica en dos sentidos: optimizar los recursos disponibles y mejorar las pautas de intervención u objetivos específicos de cada campaña. Aplicar metodologías preventivas en todas las etapas de planificación de una intervención arqueológica remitiría en una mejora de algunos de los hándicaps habituales a los que se enfrentan los restauradores. En el año 2012 vio la luz el informe realizado en Petra por la Oficina de la UNESCO en Ammán (Jordania). ${ }^{38}$ En el informe Risk Management at Heritage Sites: a

37 C. ANTOMARCHI, A. BROKERHOF y J. STEVENSON. "Reducing risks to cultural heritage: Analysis of a course metamorphosis". ICOM-CC 17th Triennial Conference Preprints, Education and Training in Conservation., 15-19 September 2014, Melbourne. ICOM-CC, Melbourne: 2014.

38 Equipo multidisciplinar con gran peso desde la Universidad de Leuven y el Centro Internacional para Conservación y Restauración Raymond Lemaire (RLICC). 
case study of the Petra World Heritage Site ${ }^{39}$ los riesgos se analizaron teniendo en cuenta: áreas arqueológicas/monumentales, senderos, tráfico dentro y fuera del parque así como las experiencias de los visitantes. El estudio se centró en detectar las vulnerabilidades, peligros y amenazas para la conservación del parque, y para ello se utilizaron distintas técnicas, como fotografía a intervalos o geo-referencial. Este trabajo nos ha servido como principal referencia para trabajar en el marco de sistemas cuantitativos/cualitativos aplicados a áreas de trabajo determinadas, como veremos en el siguiente apartado.

\section{Hacia una conservación espacial}

Tras esta introducción a las distintas metodologías utilizadas, así como inspiradas por los recientes trabajos realizados en la Ruta de la Seda, ${ }^{40}$ proponemos un nuevo método, que denominaremos Conservación espacial. Cada excavación se rige por su propio sistema de toma de datos, pero atiende habitualmente una serie de cuadrículas o áreas geográficas definidas por los topógrafos o los propios arqueólogos. Cada uno de estos espacios — que pueden contar además con unidades estratigráficas (o conjuntos de unidades) - puede ser analizado desde una perspectiva cuantitativa/cualitativa a nivel de intervención. Tipificando el número de objetos/estructuras extraídos o descubiertos, así como sus patologías, podemos crear un mapping donde determinar qué áreas tienen más o menos dificultades para su conservación a largo plazo, así como los estados de conservación de los elementos encontrados, mediante el estudio de los tratamientos que se han ido aplicando a los mismos (Tabla 3). Este mapping, al igual que sucedía con los diagramas de valor que hemos visto previamente, será un mapa dinámico que irá cambiando a medida que avancen los trabajos en el caso de aquellos yacimientos que se están excavando en la actualidad y son monitorizados.

39 G.CESARO, M. QUINTERO, A. PAOLINI, P. DE VOS, E. GLEKAS y L. VISCONTI: "Preliminary risk assessment at the Petra Archaeological Park recording strategy". International Journal of Heritage in the Digital Era, 1, 2 (2012), pp.295-312. A. VAFADARI et al.: Risk management at heritage sites: a case study of the Petra world heritage site. UNESCO, Paris, Aman: 2012.

40 O.VILEIKIS: "Connecting World Heritage nominations and monitoring with the support of the Silk Roads Cultural Heritage Resource Information System". ISPRS Annals of Photogrammetry, Remote Sensing and Spatial Information Sciences, II-5, W1 (2013), pp.319-324. 


\begin{tabular}{|c|c|c|}
\hline INDICADOR & 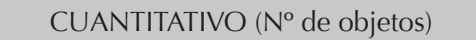 & CUALITATIVO (Descripción) \\
\hline \multirow[b]{2}{*}{ ALTERACIONES } & Estados de conservación - Tipos & $\begin{array}{l}\text { Descripción de los estados de conser- } \\
\text { vación }\end{array}$ \\
\hline & Patologías- Matriales/Tipos & $\begin{array}{l}\text { Descripción de las principales pa- } \\
\text { tologías atendiendo al tipo de material } \\
\text { extraído }\end{array}$ \\
\hline \multirow{3}{*}{$\begin{array}{l}\text { TRATAMIENTOS IN } \\
\text { SITU }\end{array}$} & Extracciones- Metodologías & $\begin{array}{l}\text { Materiales utilizados/Complejidad de la } \\
\text { intervención }\end{array}$ \\
\hline & $\begin{array}{l}\text { Consolidaciones in situ- Procedimien- } \\
\text { tos }\end{array}$ & Productos utilizados/Concentración \\
\hline & Restauración in situ - Procedimientos & Productos utilizados \\
\hline \multirow{5}{*}{$\begin{array}{l}\text { TRATAMIENTOS EN } \\
\text { LABORATORIO }\end{array}$} & Analíticas - Tipo de prueba & Descripción de resultados \\
\hline & Microexcavación & Materiales/Productos utilizados \\
\hline & Consolidación & Materiales/Productos utilizados \\
\hline & Restauración estructural & Materiales/Productos utilizados \\
\hline & Reintegración & Materiales/Productos utilizados \\
\hline \multirow{4}{*}{$\begin{array}{l}\text { ALMACENAJE O EX- } \\
\text { POSICIÓN }\end{array}$} & Creación de réplicas & Materiales/Productos utilizados \\
\hline & Nuevo estado de conservación & $\begin{array}{l}\text { Descripción de los estados de conser- } \\
\text { vación }\end{array}$ \\
\hline & Nuevas patologías & $\begin{array}{l}\text { Descripción de las principales pa- } \\
\text { tologías }\end{array}$ \\
\hline & Objetos expuestos & Descripción del espacio expositivo \\
\hline
\end{tabular}

Tabla 3. Indicadores para la Conservación Espacial (Ana Pastor y Olalla Canseco).

Para realizar este mapa (Fig. 4) deberemos tener acceso a la información generada en las excavaciones arqueológicas previas, especialmente en lo que se refiere a tratamientos de conservación-restauración. Por desgracia, no siempre existen estos datos o su acceso es muy restringido.

El deterioro de algunas estructuras visibles, o el estudio de materiales provenientes de estos espacios en colecciones expuestas, nos pueden dar pistas en relación a los tratamientos han recibido, pero la falta de registro/acceso a documentación encarecería este proceso de análisis debido al elevado precio de algunas técnicas (PIXE, RAMAN, espectrometrías...) que determinen la presencia de elementos químicos añadidos a distintas estructuras y piezas para estudiar su comportamiento en el futuro. 


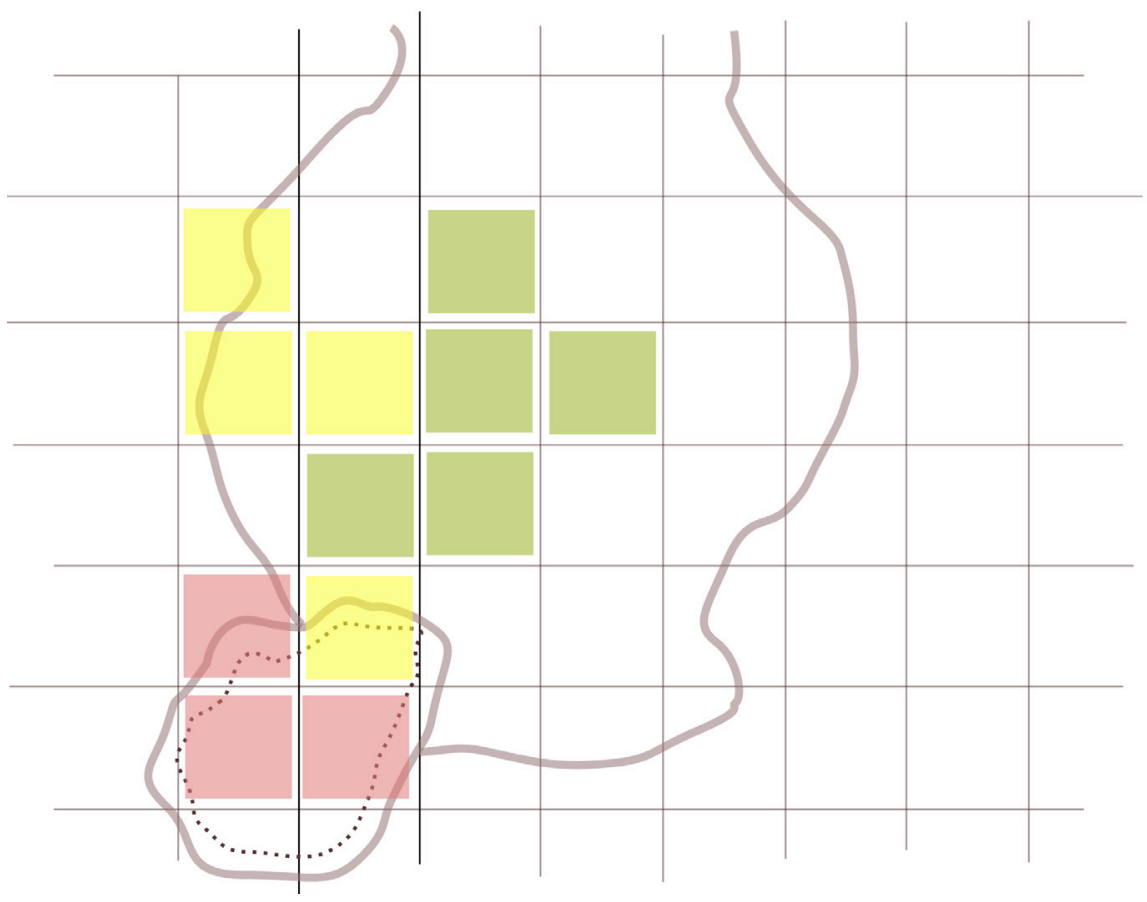

Fig. 4. Una vez estudiados los datos iremos mapeando las zonas de mayor riesgo en un color indicativo de peligro, como puede ser el rojo, amarillo para aquellas zonas que presenten retos intermedios, y verde en las que se produce un factor de riesgo menor (Ana Pastor).

Los beneficios de aplicación de este sistema son relevantes, ya que que se pueden combinar con herramientas existentes, como mapas y cartas arqueológicas en uso, aplicándose al conjunto de yacimientos de una región y determinando una serie de prioridades en la salvaguarda de los mismos:

- Generar información documental para su aplicación en distintos campos: conservación arqueológica, museología, paleontología, geología o tafonomía entre otros.

- Elegir qué zonas no deben excavarse por falta de medios técnicos/ dificultades.

- Conocer en qué áreas la excavación se verá ralentizada debido a las tareas asociadas a la conservación restauración.

- Examinar aquellos espacios donde haga falta personal muy cualificado.

- Determinar qué zonas son prioritarias para su cubrición o dejar en reserva para futuras campañas (APre). 
- Conocer cuáles serán las patologías aproximadas de los hallazgos del entorno y prever de antemano qué materiales utilizar (muy importante en yacimientos de difícil acceso o muy alejados de núcleos urbanos).

- Prever almacenamiento y condiciones del mismo para las piezas: número y condiciones ambientales.

- Optimizar los recursos económicos, de tal forma que no se invierta en materiales perecederos/fungibles que no sean necesarios.

- Mejora a largo plazo del estado de conservación del yacimiento: acercamiento hacia la autosostenibilidad del mismo.

Durante todo este proceso dinámico contaremos con un elevado nivel de incertidumbre, ya que estos datos estarán sujetos a la subjetividad de un equipo interdisciplinar con distintos puntos de vista. Aquí entrarán en juego los intereses diversos de los stakeholders. Los mapas de conservación también nos ayudan a gestionar los diagramas de valor —usados en la gestión de riesgos-que hayamos configurado. En uso combinado, podremos detectar en qué zonas hay más probabilidades de que se produzca un riesgo asociado a la acción humana durante las tareas de conservación-restauración o si una de las áreas problemáticos atiende a una de las zonas más "importantes" del conjunto. Este sistema de gestión del patrimonio, que aporta también una visión científica, nos permite conocer rápidamente cuáles son las zonas más problemáticas de nuestro yacimiento, siendo útiles tanto en las fases de excavación como en las de musealización o puesta en valor del mismo. Así podemos configurar una herramienta interdisciplinar que busque aportar soluciones sostenibles en cuanto a la conservación-restauración y puesta en valor de yacimientos arqueológicos.

\section{Problemática en la conservación arqueológica actual}

La teoría arqueológica pasa por un momento de fragmentación, dejando atrás el post-procesualismo y llevándose a cabo nuevas iniciativas más cercanas a las etnografías arqueológicas, ${ }^{41}$ estudios de paisaje, ${ }^{42}$ arqueologías comunitarias ${ }^{43} \mathrm{O}$ negativas. ${ }^{44}$ Cualquier espacio puede ser susceptible de ser estudiado con una metodología arqueológica, y es quizás a través de este estudio que se le confiere

41 Y. HAMILAKIS: "Archaeological ethnography: a multitemporal meeting ground for archaeology and anthropology". Annual Review of Anthropology, 40 (2011), pp. 399-414.

42 D. BARREIRO MARTÍNEZ: Arqueológicas. Hacia una arqueología aplicada. Bellatera, Barcelona: 2013.

43 B. J. LITTLE: "Public archaeology in the United States in the early twenty-first century" en M. L. STIG y J. CARMAN (eds.): Heritage Studies. Methods and approaches. Routledge, Londres: 2009, p.340. J. ALMANSA SÁNCHEZ: "Arqueología para todos los públicos. Hacia una definición de la arqueología pública a la española". ArqueoWeb, 13, 1 (2011), pp.87-107.

44 R. MILLÁN PASCUAL: "Arqueología Negativa. Las fronteras arqueológicas del presente", Complutum, Vol. 26,1,(2015), pp.49-69. 
una valorización; se otorgan unos atributos que lo convierten en patrimonio. ${ }^{45}$ Como indica Joel Taylor, la palabra "patrimonio" no es un objeto en sí mismo sino la razón por la cual este objeto es conservado. ${ }^{46} \mathrm{Si}$ desde hace algunos años algunos autores nos hablan de una arqueología de la supermodernidad, ${ }^{47}$ por qué no hablar también de una conservación de la supermodernidad, donde el conservador-restaurador actúa en objetos y espacios patrimoniales ${ }^{48}$ desde una perspectiva multitemporal, facilitando nuevas lecturas al registro. No debemos olvidar que el restaurador suele tener una relación directa con los objetos, suele ser el primero en tocar una pieza y en muchos casos en extraerla de forma intuitiva; un acto que irá ligado al uso "actual" de ese objeto. Posteriormente, en un laboratorio, el conservador invierte la vida del objeto intentado recuperar su forma anterior, re-escribiendo la vida de este artefacto. Todo lo anterior se simplificaría si llegásemos a un acuerdo con las autoridades y se formase un Cuerpo Oficial de Restauradores a nivel estatal, o un Colegio Oficial con el que cristalizase un corpus técnico-administrativo acompañado de un código teórico-deontológico actualizado. A lo largo de este estudio hemos analizado y propuesto nuevas técnicas que permitan optimizar los recursos existentes en el campo de la conservación-restauración en arqueología, con el objetivo de abrir nuevas vías que la conviertan en una disciplina sostenible (inversión responsable o inteligente).

La Agencia Cultural de Patrimonio de los Países Bajos, dentro de su reciente informe Asessing Museum Collections (2014) distinguió cinco categorías principales que entran en juego a la hora de evaluar las colecciones: la colección en sí misma (significancia cultural), accesibilidad, uso (valor operacional), desarrollo (valor añadido) y preservación (reducción de la pérdida de valor). Estas categorías son extrapolables también al mundo de la arqueología y nos aportan una visión global hacia la autosostenibilidad de yacimientos, teniendo en cuenta que las mejoras en la conservación del mismo revertirán en su uso/accesibilidad/desarrollo, y los beneficios que éste genere: tanto económicos como sociales. Para que eso se lograse, los conservadores-restauradores deberían estar presentes, como hemos comentado, en las etapas de planificación y toma de decisiones y no ser consultados únicamente cuando surgen las dificultades o para la realización de acciones puntales en estos espacios (Fig. 5 y 6 ).

45 C. GOULDING: "Romancing the past: heritage visiting and the nostalgic consumer". Psychology and Marketing, 18, 6 (2001), pp. 565-592.

46 J. TAYLOR: "Embodiment unbound: moving beyond divisions in the understanding and practice of heritage conservation". Studies in Conservation, 60, 1 (2015), pp.65-77.

47 A. GONZÁLEZ RUIBAL: "Time to destroy. An archaeology of supermodernity". Current anthropology: a world journal of the sciences of man, 2 (2008), pp. 247-279.

48 H. STOVEL: "Origins and influence of the Nara Document on authenticity. APT Bulletin, 39 (2008), pp.9-17. T. KOLAR y V. ZABKAR: "A consumer-based model of authenticity: An oxymoron or the foundation of cultural heritage marketing?". Tourism Management, 31, 5 (2010), pp.652-664. 


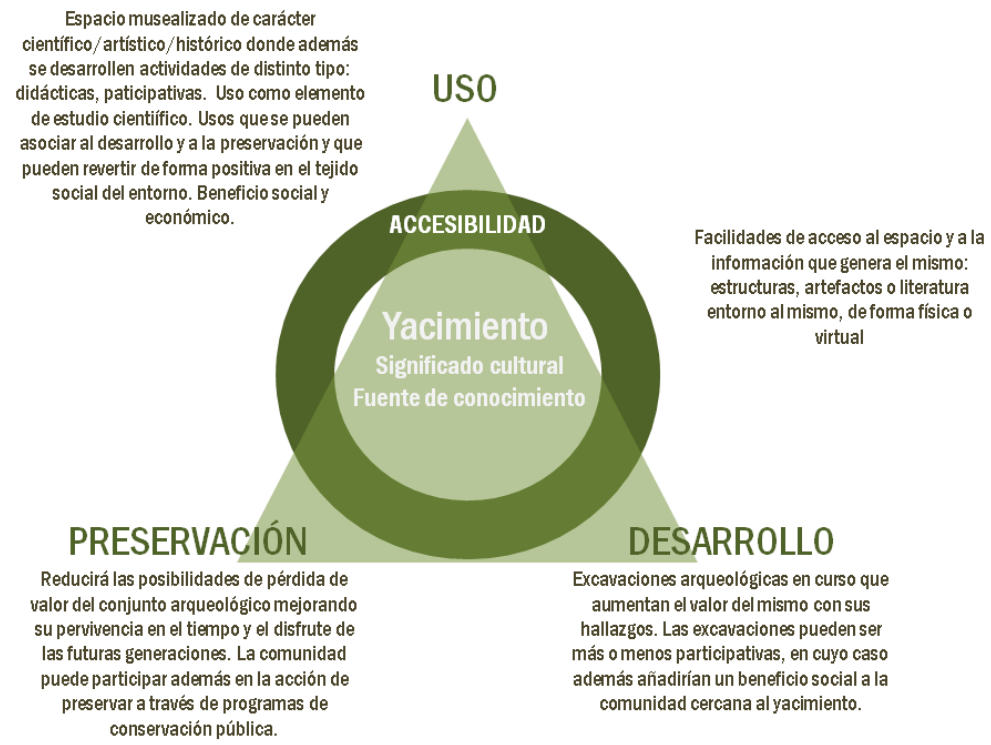

Fig. 5. Triángulo de gestión para yacimientos arqueológicos. Gráfico confeccionado por las autoras inspirado en la Agencia Cultural del Patrimonio de los Países Bajos. ${ }^{49}$

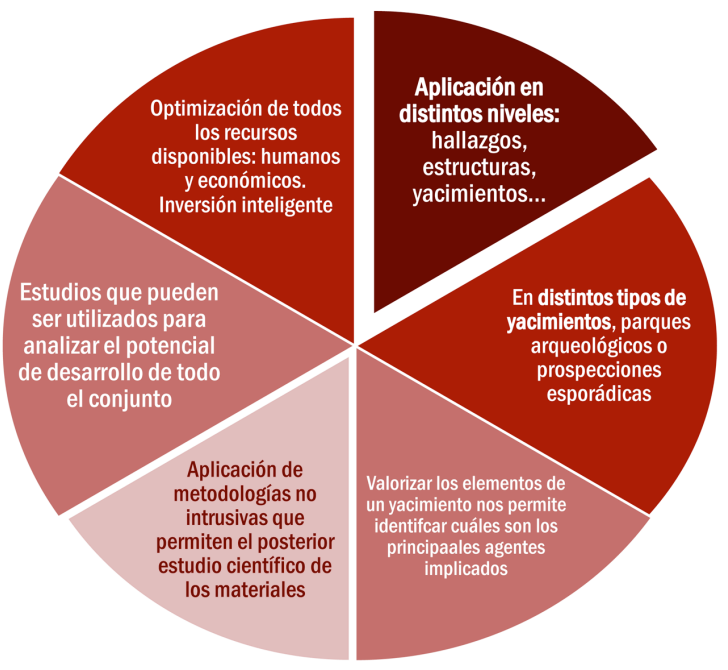

Fig. 6. Beneficios de la conservación preventiva y gestión integral de riesgos en intervenciones en el patrimonio arqueológico.

49 A. VERSLOOT (ed.): Assessing museum collections. Collection valuation in six steps. Amersfoort, The Netherlands Cultural Heritage Agency: 2014. 
La inversión inteligente a largo plazo en programas que incluyan gestión de riesgos integrados en otros sistemas ya existentes suponen un ahorro en cuanto a inversión, ya que no se trata de crear nuevas plataformas desde cero sino ampliar las funciones de aquellas ya existentes (por ejemplo, cartas arqueológicas). Se puede llevar a cabo otro tipo de conservación en el campo de la arqueología, trazando planes de emergencias para yacimientos, realizando musealizaciones no invasivas, fomentando una didáctica de la conservación-restauración. Creemos que el conservador-restaurador de la supermodernidad analizará el yacimiento como un conjunto donde conviven personas y vestigios y no únicamente a través de aquellas estructuras sobre las que tendrá que desarrollar tareas de conservación curativa o restauración.

\section{Agradecimientos}

Nos gustaría agradecer en primer lugar a Marga Lliso del Hoyo (http://margallisodelhoyo.blogspot.com.es/) su colaboración cediéndonos uno de sus dibujos para este estudio y a Marta Beltrán por sus correcciones de estilo. También damos las gracias a Maicu Ortega, restauradora de BBCC arqueopaleontológicos, amiga y compañera, que nos ha enseñado a trabajar bajo presión, pero siempre con una sonrisa. Por último, y no por ello menos importantes, a todos los compañeros de excavaciones que nos han tenido que aguantar a lo largo de nuestra vida como conservadoras-restauradoras de BBCC arqueológicos, en especial a los de los yacimientos de Pinilla del Valle (Madrid), Gavarres (Girona) y el Cerro Bilanero (Ciudad Real).

\section{Bibliografía}

N. AGNEW y J. BRIDGELAND: Of the past, for the future: integrating archaeology and conservation. Proceedings of the conservation theme at the 5th World Archaeological Congress. Getty Publications, Los Angeles: 2006, pp.53-72.

J. ALMANSA SÁNCHEZ: "Arqueología para todos los públicos. Hacia una definición de la arqueología pública a la española". ArqueoWeb, 13, 1 (2011), pp.87-107.

M.J. ALONSO LÓPEZ. "Los estudios superiores de conservación y restauración de bienes culturales". Las enseñanzas artísticas superiores en el Espacio Europeo de Educación Superior. Secretaría General de Educación, Servicio de Publicaciones, Madrid: 2010, pp.71-94.

M.J. ALONSO LÓPEZ . "Conservación preventiva en excavaciones arqueológicas: el futuro del pasado". Pátina, 8 (1997), pp.116-123. 
M.J. ALONSO y J. M. IGLESIAS: "Arqueología y conservación preventiva: una convergencia lógica". Actas de los XX Cursos Monográficos sobre el Patrimonio Histórico: [Reinosa, julio de 2009]. Universidad de Cantabria, Servicio de Publicaciones, Ayuntamiento de Reinosa: 2010, pp.123-134.

C. ANTOMARCHI, A. BROKERHOF y J. STEVENSON. "Reducing risks to cultural heritage: Analysis of a course metamorphosis". ICOM-CC 17th Triennial Conference Preprints, Education and Training in Conservation., 15-19 September 2014, Melbourne. ICOM-CC, Melbourne: 2014.

J. BALLART HERNÁNDEZ: El patrimonio histórico y arqueológico: valor y uso. Editorial Airel, Barcelona: 1997.

D. BARREIRO MARTÍNEZ: Arqueológicas. Hacia una arqueología aplicada. Bellatera, Barcelona: 2013.

D. BARREIRO MARTÍNEZ: "Arqueología y pragmatismo crítico. Hacia la renovación axiológica de la arqueología". Claves de Razón Práctica, 133 (2003), pp.36-41.

C. CABELLO-BRIONES: "A methodological approach to evaluate shelter effectiveness for the conservation of archaeological sites" en M. A. ROGERIO-CANDELERA, M. LAZZARI y E. CANO (eds.): Science and technology for the conservation of cultural heritage. CRC Press, Leiden: 2013, pp.41-44.

G. CESARO, M. QUINTERO, A. PAOLINI, P. DE VOS, E. GLEKAS y L. VISCONTI: "Preliminary risk assessment at the Petra Archaeological Park recording strategy". International Journal of Heritage in the Digital Era, 1, 2 (2012), pp.295312.

K. CLARK: "Values in cultural resource management" en G. SMITH, P. MESSENGER y H. SODERLANDS (eds.): Heritage values in contemporary society. Left Coast Press, Walnut Creek: 2009, pp. 89-99.

D. COHEN, y M. O. FERNÁNDEZ REGUERA: Valoración de colecciones. Una herramienta para la gestión de riesgos en museos. Bogotá, Museo Nacional de Colombia: 2013.

COMISIÓN EUROPEA: "Hacia una estrategia europea sobre conservación preventiva". Adoptada en la reunión de Vantaa 21-22 de septiembre de 2000. European Commission, Vantaa: 2000.

B. CULUBRET WORMS: Guía para un plan de protección de colecciones ante emergencias. Secretaría General Técnica, Ministerio de Cultura, Madrid: 2009.

I. GARCÍA FERNÁNDEZ: "Historia de la conservación preventiva. Parte II". Ge-conservación, 6, 2014, pp. 5- 18.

I. GARCÍA FERNÁNDEZ: La conservación preventiva de bienes culturales. Alianza Editorial, Madrid, 2013, pp. 25-29. 
A. GONZÁLEZ RUIBAL: Reclaiming archaeology: beyond the tropes of modernity. Routledge, Milton Park Abingdon: 2013.

A. GONZÁLEZ RUIBAL: "Time to destroy. An archaeology of supermodernity". Current anthropology: a world journal of the sciences of man, 2 (2008), pp. 247-279.

C. GOULDING: "Romancing the past: heritage visiting and the nostalgic consumer". Psychology and Marketing, 18, 6 (2001), pp. 565-592.

Y. HAMILAKIS: "Archaeological ethnography: a multitemporal meeting ground for archaeology and anthropology". Annual Review of Anthropology, 40 (2011), pp. 399-414.

V.C. HERAS y A. WIJFFELS: "A value-based monitoring system to support heritage conservation planning". Journal of Cultural Heritage Management and Sustainable Development, 3 (2013), pp.130-147.

F. HERNÁNDEZ HERNÁNDEZ: "La conservación integral del patrimonio". Complutum Extra, 6, 2 (1996), pp. 251-260.

J.A. HERRÁEZ FERREIRO: "La conservación preventiva del arte rupestre". Actas de los VII Cursos Monográficos sobre el Patrimonio Histórico: [Reinosa, julio-agosto 1996]. Universidad de Cantabria, Servicio de Publicaciones, Ayuntamiento de Reinosa: 1997, pp. 197-208.

ICOM-CC: Terminología para definir la conservación del patrimonio cultural tangible. Resolución aprobada por los miembros del ICOM-CC durante la XV Conferencia Trianual. Nueva Delhi, 22-26 de septiembre de 2008. ICOM-CC, Nueva Delhi: 2008.

ICOMOS Australia: The Australia ICOMOS charter for the conservation of places of cultural significance (the Burra charter). Australia ICOMOS, Camberra, Australia: 2013.

C. JIMÉNEZ, D. SALAZAR y P. CORRALES: "De los alcances de la arqueología: redefiniendo fronteras". Conserva, 4 (2000), pp.71-85.

T. KOLAR y V. ZABKAR: "A consumer-based model of authenticity: An oxymoron or the foundation of cultural heritage marketing?". Tourism Management, 31, 5 (2010), pp.652-664.

M. DE LA TORRE: «Values and Heritage Conservation». Heritage \& Society, 6, 2 (2013), pp. 155-166.

M. DE LA TORRE:"Values in heritage conservation: a project of the Getty Conservation Institute". APT Bulletin, 45, 2/3 (2014), pp.19-24.

K. LARSEN (ed.): Nara conference on authenticity in relation to the World Heritage Convention: Nara, Japan, 1-6 November 1994. UNESCO World Heritage Centre, Paris: 1995. 
B. J. LITTLE: "Public archaeology in the United States in the early twenty-first century" en M. L. STIG y J. CARMAN (eds.): Heritage Studies. Methods and approaches. Routledge, Londres: 2009, p.340.

D. LOWENTHAL: "Stewarding the past in a perplexing present" en E. AVRAMI, R. MASON y M. DE LA TORRE (eds.): Values and heritage conservation. . The Getty Conservation Institute, Los Angeles: 2000, pp.18-25.

S. MICHALSKI y Z. PEDERSOLI: Manual de gestión de riesgo en colecciones. UNESCO, Paris: 2009.

R. MILLÁN PASCUAL: "Arqueología Negativa. Las fronteras arqueológicas del presente", Complutum, Vol. 26,1,(2015), pp.49-69.

MINISTERIO DE EDUCACIÓN, CULTURA Y DEPORTE: Plan nacional de conservación preventiva. Ministerio de Educación, Cultura y Deporte, Madrid: 2011.

MINISTERIO DE EDUCACIÓN CULTURA Y DEPORTE: Programa de investigación para la conservación preventiva y régimen de acceso de la Cueva de Altamira (2012-2014). Ministerio de Educación, Cultura y Deporte, Madrid: 2014.

M. MURZYN-KUPISZ y J. DZIALEK: "Cultural heritage in building and enhancing social capital". Journal of Cultural Heritage Management and Sustainable Development, 3, 1 (2013), pp.35-54.

R. NARDI y K. SCHNEIDER: "Site conservation during the rescue excavations" en W. AYLWARD (ed.): Excavations at Zeugma. The Packhard Humanities Institute, Los Altos, California: 2013, pp. 55-70.

A. PASTOR PÉREZ: Conservación preventiva y sinergias con la población local: el Barrio Gótico de Barcelona a través del Pla Barcino. Trabajo de Final de Máster. Universidad de Barcelona: 2014 (Sin publicar).

M. A. QUEROL: Manual de gestión del patrimonio cultural. Akal, Madrid: 2010.

D.A. REINAR y A. M.WESTERLIND: Urban heritage analysis. A handbook about DIVE. Riksantikvaren, Oslo: 2010 [En línea en: http://brage.bibsys.no/xmlui/ handle/11250/176994]

R. RUSSELL y K. WINKWORTH: Significance 2.0: a guide to assessing the significance of collections. Collections Council of Australia, Camberra: 2009.

C. SEASE: "Book reviews: of the past, for the future: integrating archaeology and conservation presents the papers of the conservation theme at the World Archaeological Congress (WAC), Washington DC, in June 2003". Studies in Conservation, 51, 4 (2006), pp.317-319.

F. SIMPSON: The values of community archaeology: a comparative assessment between the UK and US. British Archaeological Reports International Series, Oxford: 2010. 
S. STANIFORTH: "Slow conservation". Studies in Conservation, 55 (2010), pp.74-80.

H. STOVEL: "Origins and influence of the Nara Document on authenticity. APT Bulletin, 39 (2008), pp.9-17.

J. TAYLOR: "Embodiment unbound: moving beyond divisions in the understanding and practice of heritage conservation". Studies in Conservation, 60, 1 (2015), pp.65-77.

A. VAFADARI et al.: Risk management at heritage sites: a case study of the Petra world heritage site. UNESCO, Paris, Aman: 2012.

A.VERSLOOT (ed.): Assessing museum collections. Collection valuation in six steps. Amersfoort, The Netherlands Cultural Heritage Agency: 2014.

O.VILEIKIS: "Connecting World Heritage nominations and monitoring with the support of the Silk Roads Cultural Heritage Resource Information System". ISPRS Annals of Photogrammetry, Remote Sensing and Spatial Information Sciences, II-5, W1 (2013), pp.319-324.

R. VIÑAS: "La conservación y restauración de bienes culturales en el nuevo contexto educativo español". PH Boletín del Instituto Andaluz del Patrimonio Histórico, 66, Mayo 2008, pp. 106-123. 
